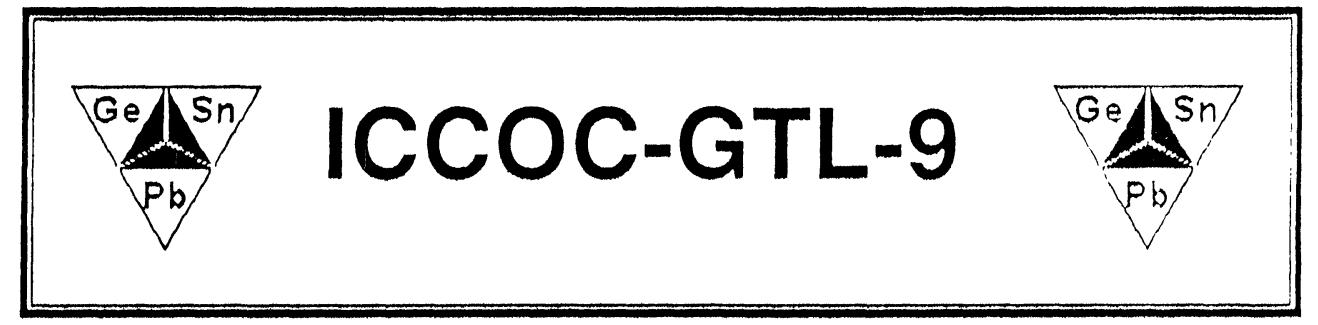

IXth INTERNATIONAL CONFERENCE ON THE COORDINATION AND ORGANOMETALLIC CHEMISTRY OF GERMANIUM, TIN, AND LEAD

Melbourne, Australia: September $20-25$ th, 1998

Encompassing the following themes:

- synthesis, structure, and reactivity - applications in organic

synthesis - cages and clusters - physical methods and theoretical calculations - reactive intermediates - polymers - biological activities - materials chemistry

The program will include a Metals in Medicine Workshop.

\title{
CALL FOR PAPERS
}

Contacts:

Professor Dainis Dakternieks, Chairman, dainis@deakin.edu.au School of Biological \& Chemical Sciences, Deakin University, Geelong, Victoria 3217, Australia

Dr Edward Tiekink, Secretary, etiekink@chemistry.adelaide.edu.au Department of Chemistry, The University of Adelaide, Australia 5005 Web site http://www.science.adelaide.edu.au/chemist/conferences/ICCOCGTL9/ 